from meiosis was thought to be due to the very small size of the chromosomes. That another interpretation must be put upon the facts regarding the tetraploid has now been shown by the following method.

In 1938 the original stocks used by Manton were communicated to Howard who treated young seedlings of the diploid with 0.5 per cent colchicine solution and thereby produced a genuine autotetraploid. It was at once apparent that this plant was not identical with the wild tetraploid. It showed all the features of darker colour, fleshier leaves and larger organs, characteristic of autopolyploids in general; but it did not show the slow growth, straggling habit and details of fruit shape that had been noted in the wild tetraploid. Moreover, its fertility was reduced and when crossed with the wild tetraploid the hybrid was highly sterile.

Investigation of meiosis by Manton has shown that whereas the wild tetraploid, as previously reported, forms 32 bivalents (the diploid forms 16), the real autopolyploid forms many quadrivalents, thus disproving the idea that their presence or absence has anything to do with chromosome size. The hybrid between wild tetraploid and the autotetraploid forms no quadrivalents but only trivalents, bivalents and a large number of univalents. The hybrid between wild tetraploid and diploid Nas. turtium officinale (that is, the triploid previously described) forms, at least in the majority of pollen mother cells, 16 bivalents and 16 univalents. It is therefore clear that each gamete produced by the wild tetraploid contains 16 chromosomes (half its total complement) which are homologous with those of the diploid and artificial autotetraploid $N$. officinale, and 16 other chromosomes which are non-homologous. The identity of the non-homologous chromosomes is not yet known, but it is expected that they will be found to belong to a species of the related genus Cardamine, particularly as the seeds in the wild tetraploid are uniseriate as found in Cardamine and not biseriate as found in diploid and artificial autotetraploid Nasturtium officinale.

In any event it is quite clear that 'wild tetraploid watercress' is not an auto- but an allo-polyploid, and in our opinion taxonomists would be well advised to treat it as a new species. It is hoped that a fuller account with illustrations will be published later.

School of Agriculture, H. W. Howard. Cambridge.

Botany Department, University of Manchester.

'Manton, I., Z. indukt. Abst.-u. Vererbgsl., 69, 132-57 (1935).

\section{Shortage of Lavender Oil}

IN NATURE of August 10, p. 193, in a note on "This Season's English Herbs", the statement is made- "a fair yield of English lavender oil may be expected for this season; more of the flowers will go to the still and less to Covent Garden in bunches for street vendors, and thus at least part of the shortage due to the lack of French oil will be made good".

When comparison is made between the acreage devoted to lavender cultivation in Great Britain with that devoted to a similar purpose in France, plus the acreage of the areas from which wild lavender is habitually collected for distillation-to say nothing of the acreage devoted to the cultivation of the hybrid lavandin-it is obvious that, quantitatively, increased distillation of English lavender will make good the deficit only to a very trifling extent. I believe that, normally, France distils about 150 times as much lavender oil as we do. Commercially, English lavender oil is also unable to make good the deficit because of the very high price it commands compared with the French oil.

Fortunately, in recent years lavender cultivation has been taken up in Kenya, and quite a good oil is produced at a price comparable with the French. Lavender oil is also distilled in Western Australia, and there is a Lavandula Stoechas oil of Portuguese origin available.

It seems certain, however, that the production of lavender water and other lavender-scented toilet requisites in Great Britain will tend to diminish and that prices will tend to rise. The sales tax will also tend to limit consumption. This is much to be regretted on grounds of public hygiene, since the antiseptic value of lavender oil, according to the well-known work of Cavel, is superior to that of phenol (carbolic acid).

The Thatched Cottage, Oxford Road,

Pangbourne, Berks. August 17.

\section{Formation of Protective Films}

IN Prof. N. F. Mott's interesting article in Nature for June 29, p. 996, he states that "in some metals, notably aluminium, oxidation stops altogether when the film has reached a thickness of the order of $10^{-6} \mathrm{~cm}$., the protective films thus formed preventing further attack".

In measurements of the electrical resistance of such films ${ }^{1} \mathrm{I}$ obtained the following roughly com. parative results :

\begin{tabular}{|c|c|c|c|c|}
\hline \multicolumn{5}{|l|}{ ilm resistance immediately af } \\
\hline polishing under paraffin.. & & & 1,651 & ohm \\
\hline After $8 \mathrm{hr}$. exposure to moist air & & .. & 2,501 & \\
\hline t $160^{\circ} \mathrm{C}$. & . & . & 4,511 & \\
\hline Heating $65 \mathrm{hr}$. at $300^{\circ} \mathrm{C}$. in & $\cdots$ & $\cdots$ & 8,381 & \\
\hline Anodic oxidation fllm.. & .. & .. & 26,300 & \\
\hline
\end{tabular}

These increases in resistance would seem to indicate closer packing made possible by recrystallization, and to show that the final film thickness on aluminium is not greatly affected, even by long exposures at higher temperatures; this is in accordance with Prof. Mott's theory.

There is further the interesting suggestion that the oxide films of aluminium and zinc will dissolve metal. This is in contrast to a cuprous oxide film, and a means by which it can be distinguished from the amorphous metal which, according to Finch $^{2}$, will dissolve metal crystals, whereas the oxide will not.

30, Pine Road, L. H. Callendar.

Didsbury,

Manchester.

August 9.

1 Proc. Roy. Soc., A, 115, 368 (1927).

2 Nature, 137, 516 (1936). 